\title{
A meta-analysis on the effect of corticosteroid therapy in Kawasaki disease
}

\author{
Bo-hui Zhu • Hai-tao Lv $•$ Ling Sun • Jian-min Zhang • \\ Lei Cao $\cdot$ Hong-liang Jia $\cdot$ Wen-hua Yan $\cdot$ Yue-ping Shen
}

Received: 4 August 2011 /Accepted: 14 September 2011 /Published online: 5 November 2011

(C) The Author(s) 2011. This article is published with open access at Springerlink.com

\begin{abstract}
The current recommended therapy for Kawasaki disease (KD) is the combination of intravenous immunoglobulin (IVIG) and aspirin. However, the role of corticosteroid therapy in KD remains controversial. Using metaanalysis, this study aimed to investigate the efficacy of corticosteroid therapy in KD by comparing it with standard IVIG and aspirin therapy. We included all related randomized and quasi-randomized controlled trials by searching Medline, the Cochrane Central Register of Controlled Trials, EMBASE, Pub Med, Chinese BioMedical Literature Database, China National Knowledge Infrastructure, and the Japanese database (Japan Science and Technology) as well as hand searches of selected references. Data collection and meta-analysis were performed to evaluate the effect of corticosteroids. Our search yielded 11 studies; 7 of which evaluated the effect of corticosteroid for primary therapy in $\mathrm{KD}$, and 4 investigated the effect of corticosteroid therapy in IVIG-resistant patients. Meta-analysis of these studies revealed a significant reduction in the rates of initial treatment failure among patients who received corticosteroid therapy in combination with IVIG compared to IVIG alone (odds ratio $(\mathrm{OR})=0.50 ; 95 \% \mathrm{CI}, 0.32 \sim 0.79 ; p=$ 0.003). Furthermore, the use of corticosteroids reduced the duration of fever and the time required for C-reactive
\end{abstract}

B.-h. Zhu $\cdot$ H.-t. Lv $(\bowtie) \cdot$ L. Sun $\cdot$ J.-m. Zhang $\cdot$ L. Cao $\cdot$

H.-1. Jia $\cdot$ W.-h. Yan

Department of Pediatric Cardiology,

Children's Hospital of Soochow University,

303 Jingde Road,

Suzhou 215003, China

e-mail: haitaosz@163.com

Y.-p. Shen

Department of Biostatistics and Epidemiology, Radiation

Medicine and Public Health School, Soochow University,

Suzhou, China protein to return to normal. Our data did not show any significant increase in the incidence of coronary artery lesions or coronary aneurysms $(\mathrm{OR}=0.67 ; 95 \% \mathrm{CI}$, $0.35 \sim 1.28 ; p=0.23)$ in the corticosteroid group. Conclusion. Corticosteroid combined with IVIG in primary treatment or as treatment of IVIG-resistant patients improved clinical course without increasing coronary artery lesions in children with acute KD.

Keywords Kawasaki disease - Coronary artery lesions . Coronary artery aneurysm $\cdot$ Corticosteroids $\cdot$ Meta-analysis

\section{Introduction}

Kawasaki disease (KD) is the leading cause of acquired heart disease among children in developed countries [18]. It is an acute, self-limited, systemic vasculitis of unknown etiology that typically presents in early childhood. The disease is characterized by fever, bilateral nonexudative conjunctivitis, erythema of the lips and oral mucosa, changes in the extremities, rash, and cervical lymphadenopathy [12]. Although the etiology of KD is unknown, clinical and epidemiological data strongly suggest an infectious origin. Identification is typically based on the presence of specific signs and symptoms with selected laboratory findings, such as C-reactive protein.

As the most important complication, coronary artery lesions may lead to myocardial infarction, ischemic heart disease, and sudden death. Since the 1980s, when intravenous immunoglobulin (IVIG) combined with high-dose aspirin was demonstrated to reduce the prevalence of coronary abnormalities [13, 16, 26], this regimen has gradually become the standard therapy for the treatment of KD. Nevertheless, approximately $15 \%$ of patients fail to 
respond to initial IVIG treatment and are more likely to develop coronary aneurysms indicating the need for alternative treatment modalities [2, 18, 24, 26, 29].

Systemic immune activation in acute phase plays an important role in the pathogenesis of $\mathrm{KD}$. Corticosteroids suppress the immune response and have strong antiinflammatory effects. Considering the pathogenesis of Kawasaki disease, it is reasonable to believe that corticosteroids would suit the disease management. However, an early study in 1979 suggested that corticosteroids were associated with increased risk of coronary aneurysms. Since then, corticosteroids were restricted in the treatment of KD [11]. However, the number of patients treated with steroids was small and flaws existed in their methodology, thus the results of this study cannot be considered conclusive. Subsequent studies suggested that corticosteroid treatment in Kawasaki disease compared with IVIG shortened the duration of fever without increasing the incidence of coronary artery lesions or serious adverse events $[13,15,16,27,28]$. The efficacy and safety of corticosteroid therapy for Kawasaki disease continue to remain controversial $[1,5,14,17,19,23,24]$. Therefore, we tried to evaluate the clinical effects of corticosteroid treatment on $\mathrm{KD}$ by performing a meta-analysis of recent clinical controlled studies in order to seek a better treatment regimen for Kawasaki disease.

\section{Methods}

\section{Search methods}

Search terms included: Kawasaki disease or mucocutaneous lymph node syndrome, hormones, glucocorticoids, prednisone, methylprednisolone, hydrocortisone, or dexamethasone. Each search consisted of a combination of a minimum of one term from each group.

Study sources included: the Cochrane Library, Medline, EMBASE, Pub Med, Chinese BioMedical Literature Database, China National Knowledge Infrastructure, and Japan Science and Technology. These databases, as well as related references, were used to identify published studies which investigated the overall effect of corticosteroids in the treatment of Kawasaki disease. All subjects are pediatric patients. Preliminary studies were first identified by screening the titles and abstracts of candidate articles. After reviewing the full text, studies meeting the inclusion criteria were finally included. Conflicts in the above process were resolved by discussion among the authors.

\section{Criteria for inclusion}

Studies were included when they met the following criteria: randomized controlled, clinical trials, case-controlled or comparison studies evaluating the efficacy of corticosteroids alone or in combination with IVIG therapy in the treatment of Kawasaki disease. All subjects in the selected studies were diagnosed with Kawasaki disease (Japan Kawasaki Disease Research Committee [9]; American Heart Association's diagnostic criteria [3]). Studies not meeting the above criteria were excluded.

Evaluation of outcome data

The following criteria were used to measure outcomes: the incidence of coronary artery lesions, duration of fever and changes in serum C-reactive protein levels after treatment, the rate of unresponsive patients to initial treatment (persistent fever lasting for more than $36 \mathrm{~h}$, temperature $>38^{\circ} \mathrm{C}$, or recrudescent fever associated with $\mathrm{KD}$ symptoms after an afebrile period, 2-7 days) [5], and the number/presence of adverse events.

\section{Statistical analysis}

Data analysis were performed with meta-analysis software (RevMan 5.0) provided by the Cochrane Collaboration net. The proportion of patients who developed coronary aneurysms and the non-responsive rate in each study were converted to odds ratio (OR) and the duration of fever and $\mathrm{C}$-reactive protein (CRP) levels after treatment were expressed with mean \pm standard deviation $(\operatorname{mean} \pm \mathrm{SD})$. Homogenous results utilized the fixed effects model (Peto method) for statistical analysis. The random effects model (DerSimonian-Laird method) was employed for heterogeneous results and the data were presented using a forest map.

\section{Results}

Description of included studies

Search of public databases and selected references using the previously described criteria yielded 510 articles. Initial evaluation of titles and abstracts identified 22 related articles. The remaining works were excluded due to duplication, non-clinical trials, or failure to meet inclusion criteria. Further evaluation of the identified 22 articles resulted in an additional elimination of 11 articles. These articles evaluated corticosteroid therapy as part of the primary treatment $(n=7)$ and as additional therapy $(n=4)$ for IVIG-resistant patients [6-8, 10, 14, 17, 19-21, 22, 25]. Six of the studies were randomized controlled studies with one prospective, multicenter, double-blind randomized controlled trial [17]. One study divided patients into two subgroups for analysis. The subjects of nine studies were Japanese and the remaining were from North America 
$[17,25]$. Characteristics of all included studies are presented in Tables 1 and 2. No significant differences in age, sex, and illness were found between the two therapy groups at enrollment. Seven studies involved a follow-up period ranging from 1 to 50 months [7, 8, 10, 17, 21, 22, 25]. Statistical analysis suggested no significant differences between age, sex, and severity of illness between the two study groups.

\section{Evaluation of outcome}

Seven studies and a total of 933 patients were included in the primary treatment regimen, of which 563 patients received corticosteroid plus conventional therapy (aspirin + IVIG) or corticosteroid with aspirin. The control group received conventional therapy or aspirin alone. Four studies and a total of 122 patients were included in additional treatment regimens. In this group, 74 patients received corticosteroid therapy after treatment with conventional therapy failed and the control groups received additional IVIG. Aspirin was administered to all patients. Metaanalyses of the incidence of coronary artery lesions are shown in Figs. 1 and 2.

\section{Coronary artery lesions}

The outcomes of administering corticosteroid as primary treatment $(n=8)$ were combined with fixed effects model. The results showed no significant increase in the incidence of coronary artery lesions (CAL) $(\mathrm{OR}=0.53 ; 95 \% \mathrm{CI}$, $0.27 \sim 1.04 ; p=0.07)$ in the corticosteroid group compared with that in the control group. In the eight studies evaluated (seven plus one subgroup study, see Shinohara et al. [22]), four showed a reduction in CAL in the corticosteroid group compared to the control with only one study showing higher incidence of CAL in the corticosteroid group; one study was not analyzed for no CAL events [21]. Subjects of one study were high-risk KD patients [20] and one was a retrospective study [22].

The use of corticosteroid therapy as additional treatment $(n=4)$ resulted in no significant increase in the incidence of CALs (OR $=0.87 ; 95 \%$ CI, 0.32 2.36; $p=0.78$ ) compared with the control group. Within the studies evaluated, two showed no significant reduction of CAL and one showed fewer CALs in the corticosteroid group. The study conducted by Hashino et al. suggested higher incidence of $\mathrm{CAL}$, with three patients experiencing transient coronary artery dilatation which returned to baseline diameter values 21 days after re-treatment [7]. Meta-analysis of the incidence of coronary artery aneurysms (CAA) at 1 month after treatment is shown in Fig. 3.

There were a total of four studies including 424 patients that evaluated the incidence of coronary artery aneurysms 1 month after the initiation of treatment. This included two randomized controlled studies. Three of the four studies evaluated corticosteroid therapy for primary treatment, and one group assessed the effects of corticosteroids on IVIGresistant patients. There were no significant differences in the incidence of coronary artery aneurysms $(\mathrm{OR}=0.67$; $95 \%$ CI, $0.35 \sim 1.28 ; p=0.23$ ) in the treatment group compared with the control group.

\section{Duration of fever after treatment}

Due to the existence of significant heterogeneity among selected studies, only four studies with similar treatment protocols were combined to evaluate the effect of corticosteroid therapy on the duration of fever after treatment. The

Table 1 Summary of patients receiving corticosteroids in initial treatment

\begin{tabular}{|c|c|c|c|c|c|c|c|c|c|c|c|}
\hline \multirow[t]{2}{*}{ Study } & \multicolumn{5}{|c|}{ Patient characteristics } & \multirow{2}{*}{$\begin{array}{l}\text { Aspirin } \\
\mathrm{mg} / \mathrm{kg} \\
\text { per day }\end{array}$} & \multicolumn{2}{|l|}{ IVIG } & \multicolumn{3}{|c|}{ Corticosteroid } \\
\hline & $\begin{array}{l}\text { Total } \\
\text { patients }\end{array}$ & $\begin{array}{l}\text { Therapy } \\
\text { group }\end{array}$ & $\begin{array}{l}\text { Sex } \\
\text { (male \%) }\end{array}$ & $\begin{array}{l}\text { Age } \\
\text { (year) }\end{array}$ & $\begin{array}{l}\text { Therapy } \\
\text { day }\end{array}$ & & $\begin{array}{l}\mathrm{g} / \mathrm{kg} \\
\text { per dose }\end{array}$ & $\begin{array}{l}\text { No. of } \\
\text { doses }\end{array}$ & $\begin{array}{l}\text { Drug } \\
\text { preparation }\end{array}$ & $\begin{array}{l}\text { Dosage } \\
\text { (mg/kg per day) }\end{array}$ & $\begin{array}{l}\text { Duration of } \\
\text { therapy (days) }\end{array}$ \\
\hline $\begin{array}{l}\text { Newburger } \\
\text { et al. [17] }\end{array}$ & 199 & 101 & 62 & 2.9 & 10 & $80-100$ & 2 & 1 & IVMP & 30 & 1 \\
\hline Inoue et al. [8] & 178 & 90 & 57.3 & 4.5 & 9 & 30 & 1 & 2 & Pred & 2 & 3 \\
\hline Okada et al. [21] & 32 & 14 & 56.3 & 2.8 & 9 & 30 & 1 & 2 & Pred & 2 & 3 \\
\hline Sundel et al. [25] & 39 & 18 & 69 & & 10 & $20-25$ & 2 & 1 & IVMP & 30 & 1 \\
\hline Okada et al. [20] & 94 & 62 & 77.4 & 2.8 & 6 & 30 & 2 & 1 & IVMP & 30 & 1 \\
\hline Jibiki et al. [10] & 92 & 46 & 48.9 & 2.3 & 7 & 30 & 0.4 or 0.5 & $4-5$ & Dex & 0.3 & 3 \\
\hline $\begin{array}{l}\text { Shinohara } \\
\text { et al. } 1 \text { [22] }\end{array}$ & 212 & 170 & - & - & 9 & 30 & 0 & 0 & Pred & 2 & Defervescence \\
\hline $\begin{array}{l}\text { Shinohara } \\
\text { et al. } 2 \text { [22] }\end{array}$ & 87 & 62 & - & - & 9 & 30 & 0.2 or 0.4 & 5 & Pred & 2 & Defervescence \\
\hline
\end{tabular}

IVMP intravenous methylprednisone, Pred prednisolone 
Table 2 Summary of patients receiving corticosteroids as additional treatment

\begin{tabular}{|c|c|c|c|c|c|c|c|c|c|c|c|}
\hline \multirow[t]{2}{*}{ Study } & \multicolumn{5}{|c|}{ Patient characteristics } & \multirow{2}{*}{$\begin{array}{l}\text { Aspirin } \\
\mathrm{mg} / \mathrm{kg} \\
\text { per day }\end{array}$} & \multicolumn{2}{|l|}{ IVIG } & \multicolumn{3}{|c|}{ Corticosteroid } \\
\hline & $\begin{array}{l}\text { Total } \\
\text { patients }\end{array}$ & $\begin{array}{l}\text { Therapy } \\
\text { group }\end{array}$ & $\begin{array}{l}\text { Sex } \\
(\text { male \%) }\end{array}$ & $\begin{array}{l}\text { Age } \\
\text { (year) }\end{array}$ & $\begin{array}{l}\text { Therapy } \\
\text { day }\end{array}$ & & $\begin{array}{l}\mathrm{g} / \mathrm{kg} \text { per } \\
\text { dose }\end{array}$ & $\begin{array}{l}\text { No. of } \\
\text { doses }\end{array}$ & $\begin{array}{l}\text { Drug } \\
\text { preparation }\end{array}$ & $\begin{array}{l}\text { Dosage }(\mathrm{mg} / \mathrm{kg} \\
\text { per day) }\end{array}$ & $\begin{array}{l}\text { Duration of } \\
\text { therapy (days) }\end{array}$ \\
\hline $\begin{array}{l}\text { Ogata S } \\
\text { et al. [19] }\end{array}$ & 27 & 14 & - & 2.5 & 9 & 30 & 2 & 1 & IVMP & 30 & 3 \\
\hline $\begin{array}{l}\text { Miura } \\
\text { et al. [14] }\end{array}$ & 15 & 7 & 66.7 & 2.6 & 9 & - & 2 & 1 & IVMP & 30 & 3 \\
\hline $\begin{array}{l}\text { Hashino } \\
\text { et al. [7] }\end{array}$ & 17 & 9 & - & 6.3 & 9 & 30 & 1 & 1 & IVMP & 20 & 3 \\
\hline $\begin{array}{l}\text { Furukawa } \\
\text { et al. [6] }\end{array}$ & 63 & 44 & 54 & 2.4 & 8 & 30 & $1-2$ & 3 & IVMP & 30 & 3 \\
\hline
\end{tabular}

mean \pm SD was used for the analysis. Because of different criteria of temperature normalization among the studies, the heterogeneity still existed among the four included studies ( $p=0.03, I^{2}=68 \%$ ); a random effects model was used for the analysis (Fig. 4).

Febrile days tended to be shorter in the corticosteroid group than that in the IVIG group in one study and were significantly shorter in two other studies. The outcome of the four studies indicates there is a significant reduction in the duration of fever after corticosteroid therapy $(\mathrm{MD}=-1.30$, $p=0.0005$ ).

Inflammatory markers

$\mathrm{CRP}$ is typically elevated in acute $\mathrm{KD}$, usually returning to normal by 6 to 10 weeks after onset of the illness. Therefore we compared the changes of CRP level in the acute phase after treatment. There were nine studies that assessed changes in CRP level after treatment $[7,8,10,14$, 17, 19-21, 25]. The differences in CRP between groups at baseline were not significant, but for obvious heterogeneity and incomplete data in six articles, only three studies were finally evaluated by meta-analysis $[10,14,19]$. As a result, outcomes of two studies indicated that CRP decreased more rapidly after corticosteroid therapy and one showed no significant difference. Combined analysis showed a significant statistical difference in CRP level after two therapy regimens $(\mathrm{MD}=-0.16, p=0.02)$ (data not shown).

The rate of non-response to initial treatment

Five studies with 601 patients were analyzed, the number of non-responsive patients were those with persistent fever lasting for more than $36 \mathrm{~h}$ (temperature $>38^{\circ} \mathrm{C}$ ) or recrudescent fever associated with $\mathrm{KD}$ symptoms after an afebrile period (2-7 days). The meta-analysis is shown in Fig. 5.

Four of the included studies were randomized controlled trials, while one was a quasi-randomized controlled study. All four randomized controlled studies showed a lower non-response rate to corticosteroid therapy than to IVIG alone. The remaining study showed no significant differences

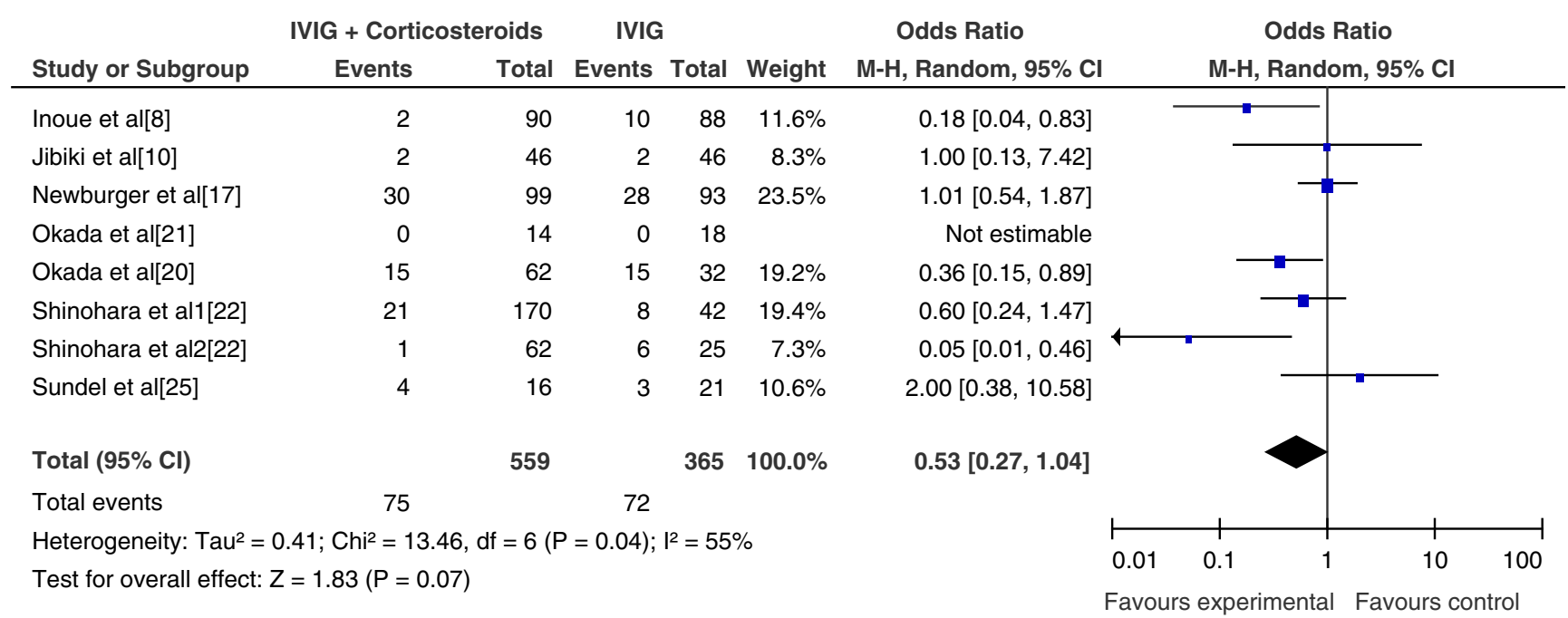

Fig. 1 The incidence of coronary artery lesions after primary treatment 


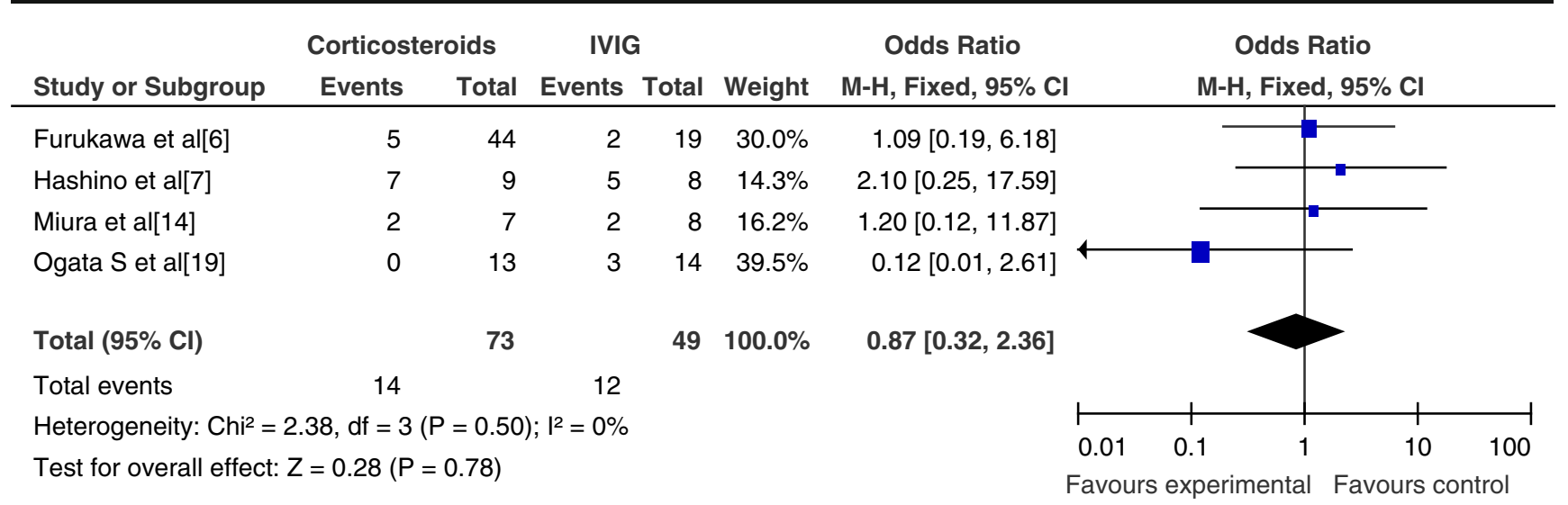

Fig. 2 The incidence of coronary artery lesions following failure of primary treatment and after secondary treatment. Secondary treatment consisted of either corticosteroids or a second round of IVIG

between the two therapy protocols in which patients received dexamethasone $0.3 \mathrm{mg} / \mathrm{kg}$ per day for 3 consecutive days. Combining outcomes of the five studies demonstrated a significant reduction in the number of patients needing re-treatment between the two therapy regimens $(\mathrm{OR}=0.50$; 95\% CI, 0.32 0.79; $p=0.003$ ).

\section{Additional clinical outcomes}

There were four included studies that compared hospitalization days and cost in the corticosteroid group with that in the IVIG group. Six studies were excluded in the present meta-analysis of CRP, but their respective results regarding CRP were consistent with this study. Three studies confirmed that corticosteroid therapy reduced the duration of hospital stay and costs. However, Newburger et al. [17] reported dissimilar results. They concluded that two matched groups had similar total number of days in the hospital (including readmissions) and days of fever after the onset of illness or after randomization. Two included articles also investigated the effects of corticosteroid (added to primary therapy or as part of additional treatment) on serum cytokine levels in the acute phase of KD. The findings demonstrated that TNF- $\alpha$ and MCP-1 were significantly inhibited after steroid therapy [14], which suggests steroid therapy may prevent the development of coronary aneurysm and improve clinical signs and symptoms.

Adverse events related to steroid therapy included sinus bradycardia, hypothermia, hypertension, and hypokalemia; all of which were transient and later spontaneously recovered [6, 8, 17, 19, 20]. Newburger et al. reported four serious events, including shock, profound sensorineural hearing loss, and respiratory failure with negative blood cultures 3 days after initial hospital discharge in the methylprednisolone group [17]. They also reported a possible nonocclusive thrombus in the right coronary artery by echocardiography in the control group. One study reported that one patient in the IVIG group developed shock shortly after IVIG administration [8] and Okada et al. found some patients developed transient AST elevation [20]. Sundel et al. reported that one patient in the steroid group developed idiopathic thrombocytopenic purpura and later died due to bilateral pulmonary and left cerebellar hemorrhages [25]. This was not believed to be related to $\mathrm{KD}$ or steroid treatment.

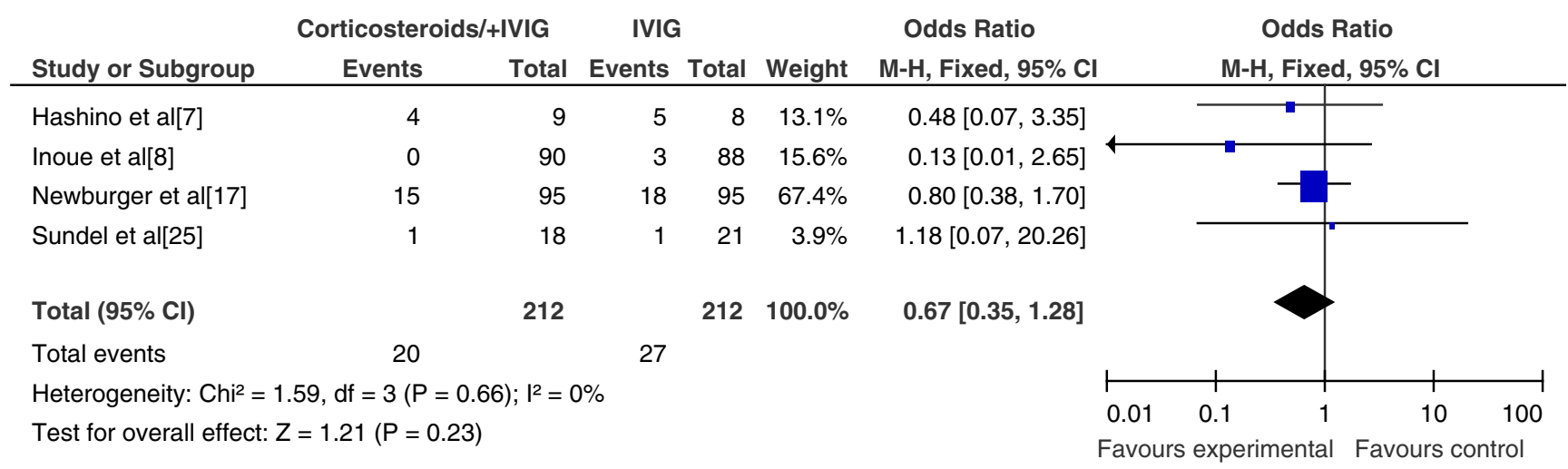

Fig. 3 The incidence of coronary artery aneurysms at 1 month after treatment 


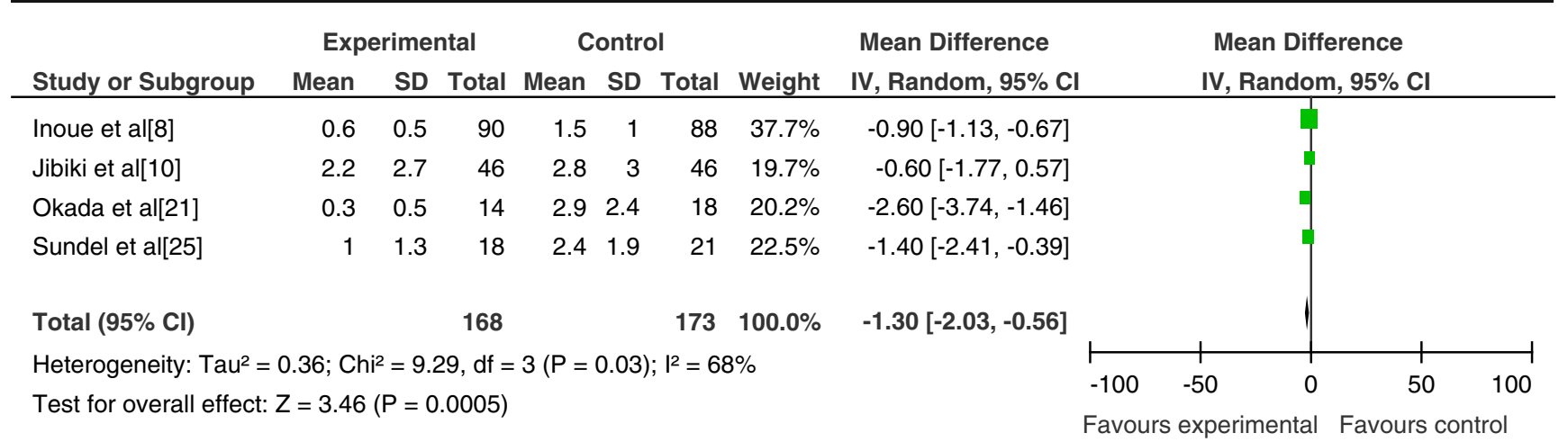

Fig. 4 Comparison of the duration of fever after treatment in patients that received corticosteroid plus IVIG or IVIG alone

\section{Discussion}

Forty years have passed since the first description of Kawasaki disease, yet the etiology remains unknown. Therefore the optimal treatment awaits identification of the specific agent or agents and pathogenic mechanisms of the disease. Presently, IVIG and aspirin are the recommended standard therapy for treatment with the occasional use of steroids. However, the role and potential adverse effects of the use of steroids in KD remain controversial. There have been recent reports of successful management of IVIG-resistant patients and patients with serious complications of KD receiving additional steroid therapy resulting in no serious adverse effects [4, 8, 14]. Additional studies have reported the use of steroids as part of the primary treatment with no increase in the incidence of coronary artery lesions, shortened hospitalization days and duration of fever, reduced CRP, erythrocyte sedimentation rate, and other inflammatory indictors [8, 10, 17, 21, 25]. We believe this data supports the need to reevaluate the role of corticosteroid in Kawasaki disease.

This meta-analysis is a systematic review integrating results of individual studies in a quantitative method. With the increase in use of evidence-based medicine in recent years, meta-analysis has become an important tool in clinical medicine. Although it can be difficult to avoid publication bias, this type of examination improves the test power by combining several small clinical trials into a large clinical trial, especially when the results of the included studies contain inconsistencies. This analysis systematically evaluated the efficacy and safety of corticosteroid therapy in KD.

Comparison of the incidence of coronary artery lesions

Whether in primary treatment or as additional treatment, our study does not indicate a significant increase in the incidence of coronary artery lesions following steroid therapy. Yet, one study showed a lower incidence of CAL in the steroid group compared to the control; we considered this was the result of missing data. Two patients missed echocardiograms at the 2 -week visit that were included at the 1-month follow-up echocardiogram. The data indicated no significant difference in the incidence of coronary artery aneurysms between the two groups at this time point; therefore, indicating steroid therapy does not increase the incidence of coronary artery aneurysms, irrespective of whether it was used as primary treatment or as additional

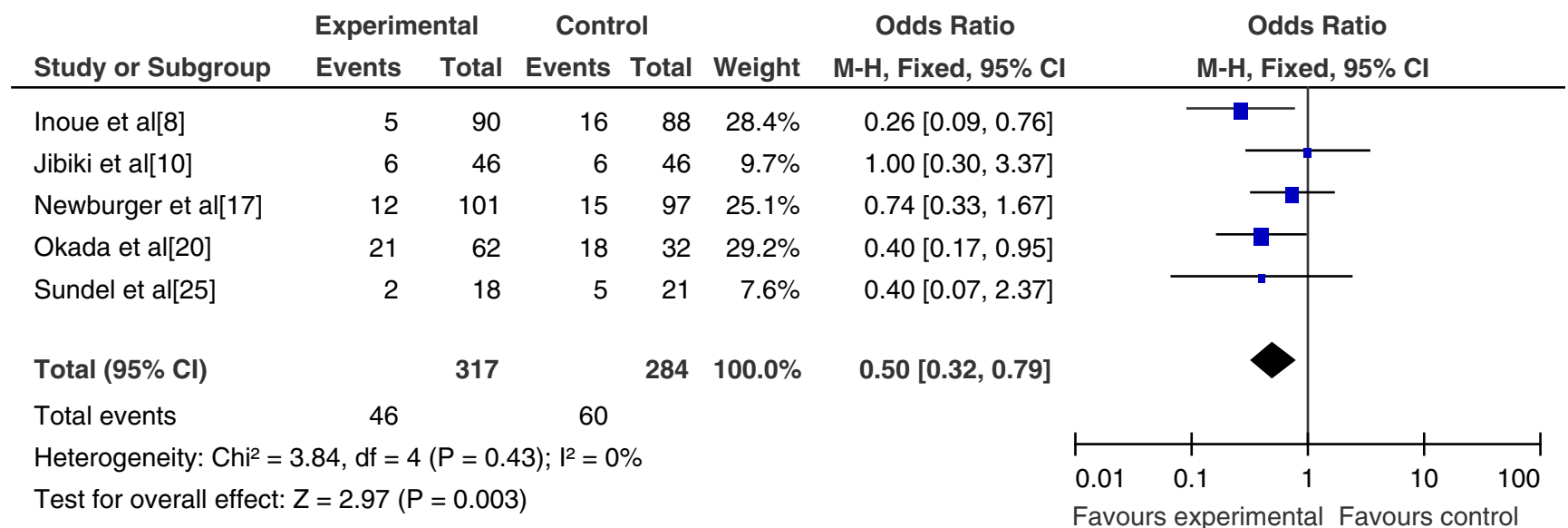

Fig. 5 The rate of unresponsive patients to initial treatment 
treatment for IVIG resistant. On the contrary, there have been reports indicating that high-risk KD patients or IVIGresistant patients treated with corticosteroid displayed a reduction in the incidence of coronary aneurysms $[8,20]$.

Results of patients non-responsive to standard therapy

Analysis of four randomized controlled studies showed a marked decrease in the number of febrile patients after corticosteroid therapy. These data indicated that corticosteroid therapy does not increase the incidence of coronary artery lesions in high-risk children or patients refractory to IVIG therapy. Although the use of steroids did not significantly reduce the risk of coronary artery lesions in children with $\mathrm{KD}$, our data demonstrated it does shorten the duration of fever and reduce the number of patients requiring re-treatment with IVIG or other pharmacologic protocols. Several studies suggested that corticosteroids improved the laboratory inflammatory findings and made C-reactive protein and cytokines levels decrease rapidly in the acute phase of $\mathrm{KD}[8,14,20,21,25]$. In contrast, a randomized study by Newburger et al. demonstrated that pulse intravenous methylprednisolone $(30 \mathrm{mg} / \mathrm{kg}$ over 2 to $3 \mathrm{~h}$ ) administered before IVIG in primary treatment did not improve coronary artery outcome or reduce the total days of hospitalization or fever [17]. Although important, these differences may be attributed to differences in protocols of corticosteroid therapy. The data supports the beneficial use of corticosteroid in the treatment of Kawasaki disease for primary treatment or as additional treatment after initial therapy failure. According to the results of this study and previous reports, IVIG therapy is not completely effective and alternative primary or additional therapies should be considered. The present power of the prediction of nonresponse rate to initial therapy with IVIG alone is limited and the late sequelae of systemic vasculitis remain unknown in KD patients, even in those without acute coronary artery injury [20]. Undoubtedly, coronary lesions are the greatest risk of fatality in predominant determinants of its outcome; moreover, a full picture of the outcome of Kawasaki disease remains unclear. So the application of corticosteroid to treating Kawasaki disease deserves further discussion.

\section{Limitations}

The majority of reports using corticosteroid therapy in Kawasaki disease are retrospective studies often with an increase in bias due to a lack of experimental controls. Randomized controlled studies are one of the most rigorous experimental designs utilized in evidence-based medicine; only six of the included studies in this report were randomized controlled studies. However, the dosage and administration of corticosteroid, immunoglobulin, aspirin, and other additional drugs varied among the included studies (see Tables 1 and 2). Furthermore, the studies included were of small sample size and could contribute to bias. Therefore, to further verify the efficacy and safety of steroid therapy in the treatment of Kawasaki disease, larger, prospective, multicenter, randomized controlled studies should be conducted.

Acknowledgments This work was financially supported by the Jiangsu Province Natural Science Foundation (No. BK2010232). Additionally, we would like to thank Medjaden Bioscience Limited general office of Hong Kong for their assistance in manuscript editing.

Conflicts of interest None of the authors had declared a conflict of interest.

Open Access This article is distributed under the terms of the Creative Commons Attribution Noncommercial License which permits any noncommercial use, distribution, and reproduction in any medium, provided the original author(s) and source are credited.

\section{References}

1. Bianca Lang MD (2002) Controversy in the management of Kawasaki disease. Best Pract Res Clin Rheumatol 16(3):427-442

2. Burns JC, Capparelli EV, Brown JA, Newburger JW, Glode MP (1998) Intravenous gamma-globulin treatment and retreatment in Kawasaki disease. Pediatr Infect Dis J 17:1144-1148

3. Council on Cardiovascular Disease in the Young, Committee on Rheumatic Fever, Endocarditis, and Kawasaki Disease, American Heart Association (2001) Diagnostic guidelines for Kawasaki disease. Circulation 103:335-336

4. Dale RC, Saleem MA, Daw S, Dillon MJ (2000) Treatment of severe complicated Kawasaki disease with oral prednisolone and aspirin. J Pediatr 137:723-726

5. Freeman AF, Shulman ST (2004) Issues in the diagnosis of Kawasaki disease. Prog Pediatr Cardiol 19(2):123-128

6. Furukawa T, Kishiro M, Akimoto K, Nagata S, Shimizu T, Yamashiro Y (2008) Effects of steroid pulse therapy on immunoglobulin-resistant Kawasaki disease. Arch Dis Child 93:142-146

7. Hashino K, Ishii M, Iemura M, Akagi T, Kato H (2001) Retreatment for immune globulin-resistant Kawasaki disease: a comparative study of additional immune globulin and steroid pulse therapy. Pediatr Int 43:211-217

8. Inoue Y, Okada Y, Shinohara M, Kobayashi T, Tomomasa T, Takeuchi K, Morikawa A (2006) A multicenter prospective randomized trial of corticosteroids in primary therapy for Kawasaki disease: clinical course and coronary artery outcome. J Pediatr 149:336-341

9. Japan Kawasaki Disease Research Committee (1984) Diagnostic guidelines of Kawasaki disease. 4th rev. Japan Kawasaki Disease Research Committee, Tokyo

10. Jibiki T, Terai M, Kurosaki T, Nakajima $H$, Suzuki K, Inomata $H$, Terashima I, Honda T, Yasukawa K, Hamada H, Kohno Y (2004) Efficacy of intravenous immune globulin therapy combined with dexamethasone for the initial treatment of acute Kawasaki disease. Eur J Pediatr 163:229-233 
11. Kato H, Koike S, Yokoyama T (1979) Kawasaki disease: effect of treatment on coronary artery involvement. Pediatrics 63:175-179

12. Kawasaki T, Kosaki F, Okawa S, Shigematsu I, Yanagawa $H$ (1974) A new infantile acute febrile mucocutaneous lymph node syndrome (MCLS) prevailing in Japan. Pediatrics 54:271-276

13. Kijima Y, Kamiya T, Suzuki A, Hirose O, Manabe H (1982) A trial procedure to prevent aneurysm formation of the coronary arteries by steroid pulse therapy in Kawasaki disease. Jpn Circ J 46:1239-1242

14. Miura M, Kohno K, Ohki H, Yoshiba S, Sugaya A, Satoh M (2008) Effects of methylprednisolone pulse on cytokine levels in Kawasaki disease patients unresponsive to intravenous immunoglobulin. Eur J Pediatr 167:1119-1123

15. Miura M, Ohki H, Yoshiba S, Ueda H, Sugaya A, Satoh M (2005) Adverse effects of methylprednisolone pulse therapy in refractory Kawasaki disease. Arch Dis Child 90:1096-1097

16. Newburger JW (1999) Treatment of Kawasaki disease: corticosteroids revisited. J Pediatr 135:411-413

17. Newburger JW, Sleeper LA, McCrindle BW, Minich LL, Gersony W, Vetter VL, Atz AM, Li JS, Takahashi M, Baker AL, Colan SD, Mitchell PD, Klein GL, Sundel RP, Investigators Pediatric Heart Network (2007) Randomized trial of pulse corticosteroid therapy for primary treatment of Kawasaki disease. N Engl J Med 356:663-675

18. Newburger JW, Takahashi M, Gerber MA, Gewitz MH, Tani LY, Burns JC, Shlman ST, Bolger AF, Ferrieri P, Baltimore RS, Wilson WR, Baddour LM, Levison ME, Pallasch TJ, Falace DA, Taubert KA (2004) Diagnosis, treatment, and long-term management of Kawasaki disease. Circulation 110:2747-2771

19. Ogata S, Bando Y, Kimura S, Ando H, Nakahata Y, Ogihara Y, Kaneko T, Minoura K, Kaida M, Yokota Y, Furukawa S, Ishii M (2009) The strategy of immune globulin resistant Kawasaki disease: a comparative study of additional immune globulin and steroid pulse therapy. J Cardiol 53:15-19
20. Okada K, Hara J, Miki I, Miki K, Matsuzaki K, Matsuoka T, Yamamoto T, Nishigaki T, Kurotobi S, Sano T, Osaka Kawasaki Disease Study Group (2009) Pulse methylprednisolone with gammaglobulin as an initial treatment for acute Kawasaki disease. Eur J Pediatr 168:181-185

21. Okada Y, Shinohara M, Kobayashi T, Inoue Y, Tomomasa T, Kobayashi T, Morikawa A, Gunma Kawasaki Disease Study Group (2003) Effect of corticosteroids in addition to intravenous gamma globulin therapy on serum cytokine levels in the acute phase of Kawasaki disease in children. J Pediatr 143:363-367

22. Shinohara M, Sone K, Tomomasa T, Morikawa A (1999) Corticosteroids in the treatment of the acute phase of Kawasaki disease. J Pediatr 135:465-469

23. Shulman S (2003) Is there a role for corticosteroids in Kawasaki disease? J Pediatr 142:601-603

24. Shulman ST, Rowley AH (2004) Advances in Kawasaki disease. Eur J Pediatr 163:285-291

25. Sundel RP, Baker AL, Fulton DR, Newburger JW (2003) Corticosteroids in the initial treatment of Kawasaki disease: report of a randomized trial. J Pediatr 142:611-616

26. Wallace CA, French JW, Kahn SJ, Sherry DD (2000) Initial intravenous gammaglobulin treatment failure in Kawasaki disease. Pediatrics 105:e78

27. Wooditch AC, Aronoff SC (2005) Effect of initial corticosteroid therapy on coronary artery aneurysm formation in Kawasaki disease: a meta-analysis of 862 children. Pediatrics 116:989-995

28. Wright DA, Newburger JW, Baker A, Sundel RP (1996) Treatment of immune globulin-resistant Kawasaki disease with pulsed doses of corticosteroids. J Pediatr 128:146-149

29. Yanagana H, Nakamura Y, SakataK YM (1997) Use of intravenous gamma-globulin for Kawasaki disease: effects on cardiac sequelae. Pediatr Cardiol 18:19-20 